\title{
THE WORKPLACE ATTACHMENT STYLES QUESTIONNAIRE IN SHORTENED 9-ITEM VERSION
}

\author{
Kristína Mrázková, \& Elena Lisá \\ Institute of Applied Psychology, Faculty of Social and Economic Sciences, Comenius University
} (Slovakia)

\begin{abstract}
Introduction: Place attachment is multi-dimensional and depends on a reciprocal relationship between behavior and experience. It comes from environmental psychology, and it has its roots in the theory of attachment because of an emotional link between an individual and a place. The present paper aims to describe the psychometric characteristics of the Slovak version of The Workplace Attachment Styles Questionnaire (Srima, 2018). Methods: The original questionnaire consists of 15 items with a Likert scale ranging from totally disagree to agree. The research sample consisted of 645 working adults of a convenience sample, aged from 16 to 78 years, consisting of 54.9\% women, from various work fields (finance, sales, education). We randomly divided the sample into two halves for separate studies. Results: In the first study with 323 adult participants, we used exploratory factor analysis to examine its construct validity. According to exploratory factor analysis, we reduced the 15-item questionnaire to a 9-item structure with three original factors: secure $(\mathrm{AM}=6.23, \mathrm{SD}=2.32)$, dismissive $(\mathrm{AM}=3.64, \mathrm{SD}=2.54)$, and preoccupied $(\mathrm{AM}=3.64, \mathrm{SD}=2.31)$ workplace attachment styles, with an average internal consistency of 0.75 . In the second study with 322 participants, we executed the confirmatory factor analysis, which confirmed the three-factor structure, with an average internal consistency of 0.65 . Discussion: The results confirmed the original three-factor structure of The Workplace Attachment Styles Questionnaire with 9 original items instead of 15. This paper contributes to the shorter version of the Workplace Attachment Styles questionnaire adapted to the Slovak population. The study's limitations are the absence of other measurement tools that could verify the construct of workplace attachment itself (Adult Attachment in the Workplace, Experience in Close Relationship Questionnaire). That is also what is worth doing in the next research.
\end{abstract}

Keywords: Workplace attachment, attachment styles, secure, dismissive, preoccupied.

\section{Introduction}

Attachment is a widely studied construct rooted in human biological nature. The field of attachment research initially encompasses only the emotional bond between the infant and the mother (Bowlby 2010). Gradually, children's behavior after separation from their mothers began to be studied, and attachment methods ensued. Thus, attachment styles emerged that made it easier to identify individuals' behavior in interactions with others (Ainsworth 1979). Further research focused on attachment styles' stability over time and confirmed their relative stability through school age (Main et al. 1985). In time, the research field focused on transferring attachment from childhood to adulthood and close relationships (Hazan \& Shaver 1994). However, only a few studies have focused on attachment in an organizational context (Scrima 2014, 2017).

Place attachment bases on the roots of urban sociology, human geography, and environmental psychology. Within environmental psychology, place attachment is an interdisciplinary concept that contributes to merging different scientific disciplines. It emphasizes the symbolic meaning for people and the strength of the emotional relationship with the place (Naništová 1998). Under this approach, place attachment has been measured with one-dimensional scales used in several studies (Bonaiuto, Fornara, \& Bonnes 2003; Rioux \& Mokounkolo 2005; Velasco \& Rioux 2010). The best known one-dimensional scale for examining workplace attachment is The Workplace Attachment Scale (Rioux 2006), which defines workplace attachment as an emotional bond that results from the dynamic interaction between employees and the organizational environment and is an essential aspect of the quality of work life. The relationship between attachment theory and workplace attachment primarily concerns the emotional bonds individuals form with the physical environment (Giuliani 2003). Scrima et al. were the first to 
examine workplace attachment within the organizational environment (Scrima et al. 2014, 2017), focusing on the relationships between workplace attachment and attachment styles (Scrima 2018). Scrima also developed a methodology for measuring workplace attachment styles - The Workplace Attachment Style Questionnaire. According to the study, securely attached workers have more positive attitudes toward work, more substantial organizational commitment, and greater engagement at work. When they can adapt to the job, their overall performance, quality of work/life, and well-being increased. Ambivalently attached workers are more emotionally attached to the work environment and more fearful of losing their jobs. Overall emotional devotion to work is more characteristic of insecure attachment styles. Increasing the employee's commitment to the organization is also influenced mainly by participation in organizational life (Scrima et al., 2015).

The aim of creating The Workplace Attachment Style Questionnaire was to identify the intensity of attachment and the quality of workplace attachment - i.e., the existence of four workplace attachment styles, based on a two-dimensional model by Bartholomew and Horowitz (1991). The first dimension, "Thoughts of Self" is a mental representation of oneself. The second dimension of "Thoughts of Place" is an emotional and cognitive representation of place. Both dimensions carry a positive and a negative charge, and their different combinations can result in 4 styles of workplace attachment - i.e., secure, dismissive, preoccupied, and fearful workplace attachment style. Scrima (2018), together with three experts, created a list of items most consistent with the assessment of workplace attachment. The fearful style was not included in the questionnaire because it is associated with the clinical population and is less probable in employed people (Levy 2005). A subsequent content analysis, which resulted in excluding redundant items, yielded a list of 33 items. An exploratory factor analysis took place to examine the factor structure of the scale. Following EFA (factor weighting into two factors, low factor weighting, and semantically inconsistent items), the 33-item scale was reduced to 15 items answered on a 5-point Likert scale ranging from "Totally Disagree" to "Totally Agree." In a sample of 342 Italian employees working in the public and private sectors, the authors found a three-factor solution based on an exploratory factor analysis, including secure, dismissive, and preoccupied workplace attachment style. The questionnaire has high internal reliability ( 0.83 to 0.91$)$ in all three dimensions. In the second study on a sample of 226 Italian workers, confirmatory factor analysis confirmed the three-factor model's suitability.

This study aims to test the validity of the Slovak translation of the Workplace Attachment Style Questionnaire. We suppose that the Slovak translation of WASQ is a 3-dimensional construct (exploratory factor analysis). We suppose the best fit for a model with a 3-factor structure. At the same time, we aim to find out the correlations and differences between sociodemographic variables.

\section{Methods}

We used the approach used by the author of the questionnaire in the review of the WASQ (Scrima 2018). 706 questionnaires were distributed, with a response rate of $93.76 \%$. Of the 662 questionnaires, we excluded an additional 17 due to incomplete data. We randomly divided the research sample into two halves. Thus, the paper contains two research studies. In study 1 , we tested the 3 -factor structure of the WASQ questionnaire using EFA. In study 2, we confirm the appropriateness of the 3-factor model using CFA.

\subsection{Methods of study 1}

Our sample consisted of 323 participants aged 16 to 78 years $(M=37.09$; $\mathrm{SD}=11.74)$, of whom $42.4 \%$ were men and $53.9 \%$ were women. Participants were working adults or part-time employees from various labor market sectors (finance, business, education). Length of organizational tenure from 0.20 years to 40 years $(M=5 ; S D=5.47) .13 .6 \%$ of the sample were managers, and $86.4 \%$ were subordinates. Participants got information that participation in the study was voluntary and anonymous and signed an informed consent form. They received the Workplace Attachment Style Questionnaire (Scrima 2018) in the paper form, which was translated into Slovak by two independent psychologists by consensus. They answered the questionnaire on a 5-point Likert scale from 0 - strongly disagree to 4 - strongly agree. In addition to the questionnaire, the participants also filled in sociodemographic variables such as age, gender, organizational tenure, and professional status.

As for data analysis, we used Exploratory factor analyses using the Principal Axes factoring extraction method with Direct Oblimin rotation, Cronbach's alphas, Spearmen's correlation analysis, and Mann-Whitney U test.

\subsection{Results of study 1}

Based on the exploratory factor analysis, we reduced the number of items from 15 to 9. We eliminated items with a factor weight of less than 0.30 and those with a factor weight in at least two 
factors. Thus, items 3, 5, 8, 9, 10, and 12 were excluded. Table 1 shows the final three-factor model with 9 items explaining $55.97 \%$ of the variance. According to the Kaiser-Meyer-Olkin test $(\mathrm{KMO}=0.797$, $\mathrm{p}=0.000$ ), the data are sufficient for use in factor analysis. The first one corresponds to the dismissive style of workplace attachment $(\mathrm{AM}=3.64, \mathrm{SD}=2.54)$ with $34.97 \%$ of the explained variance. This dimension contains three items (e.g., "In my organization, I prefer to avoid some jobs, even if it hinders my work."). Cronbach's alpha $=0.803$. The second factor secure workplace attachment style $(\mathrm{AM}=6.23$, $\mathrm{SD}=2.32)$, which provides $13.21 \%$ explained variance with Cronbach's alpha $=0.639$, contains 3 items (e.g., "My workplace is like me"). The third factor is preoccupied workplace attachment style $(\mathrm{AM}=3.64, \mathrm{SD}=2.31)$, with three items (e.g., "My workplace sometimes feels oppressed"), yields 5.5\% explained variance with Cronbach's alpha $=0.706$. The correlation matrix in Table 2 shows a significant negative correlation between the secure style and the preoccupied style. Two insecure styles correlated significantly with each other at the level $(\rho=0.609, \mathrm{p}<0.001)$. A weak positive correlation was between the secure style and organizational tenure. Within gender, there was a small factual difference in dismissive style. There was no statistically significant difference between attachment styles and labor market sectors.

Table 1. Exploratory factor analysis of WASQ.

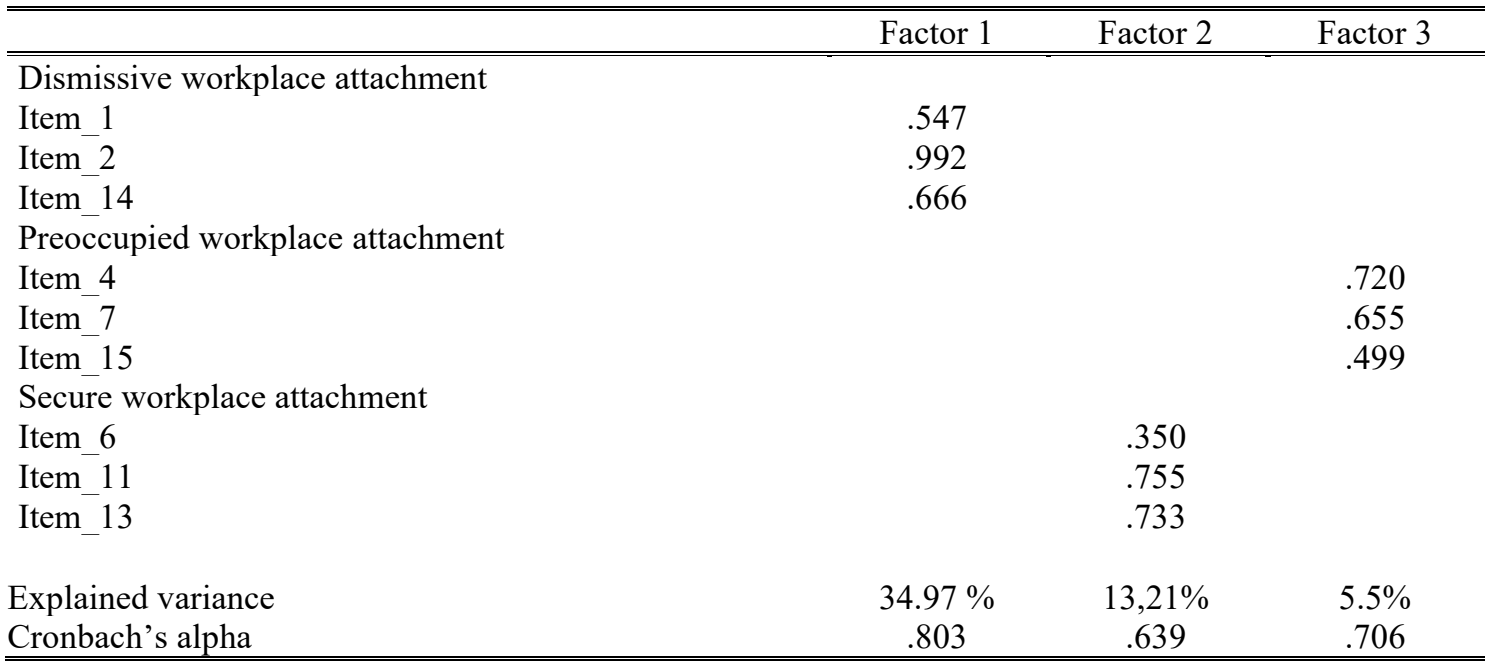

Table 2. Correlations between attachment styles and sociodemographic variables.

\begin{tabular}{|c|c|c|c|c|c|}
\hline & 1 & 2 & 3 & 4 & 5 \\
\hline 1. Secure style & 1 & & & & \\
\hline 2. Dismissive style & -.093 & 1 & & & \\
\hline 3. Preoccupied style & $-.215^{* *}$ & $.609^{* *}$ & 1 & & \\
\hline 4. Age & .070 & -.066 & -.094 & 1 & \\
\hline 5. Organizational tenure & $.194^{* *}$ & .042 & .060 & $.441^{* *}$ & 1 \\
\hline
\end{tabular}

\subsection{Methods of study 2}

In the second study, the research sample consisted of 322 participants aged 18 to 70 years $(\mathrm{M}=38.63, \mathrm{SD}=10.85)$. Of these, $41.1 \%$ were men, and $47.5 \%$ were women. The organizational tenure ranged from less than one year to 27 years $(M=5.77, \mathrm{SD}=5.19) .14 .6 \%$ of the sample were leaders, and $85.3 \%$ were subordinates.

We performed confirmatory factor analysis based on structural equation modeling (SEM) to confirm the factor structure. Parameters were estimated with the robust maximum likelihood method (ML), and we used the software lavaan (Satorra \& Bentler 1994). The parameters were also estimated using the robust Tuker -Lewis Index (TLI), with a value greater than 0.90, then the robust comparative fit index (CFI), with values ranging from 0 to 1 . A value greater than 0.95 indicates a good model fit (Hu \& Bentler, 1999). The robust Root Mean Square Error of Approximation (RMSEA) ranges from 0 to 1, where the smaller value indicates the better model fit. According to Brown (2015), a value of 0.06 or less is an acceptable model fit indicator. Finally, we used robust standardized Root Mean Square Residuals (SRMR), ranging from 0 to 1 , with values less than 0.80 being a criterion for an acceptable model (Hu \& Bentler 1999). 


\subsection{Results of study 2}

Figure 1 shows the structure of a shortened version of the WASQ. All items (structural parameters) correlated with factors at the level of $p<0.001$. Correlations between factors were confirmed only for two insecure styles $(\mathrm{r}=0.65, \mathrm{p}<0.001)$. For secure style, the correlation was not confirmed $(\mathrm{r}=-0.19, \mathrm{p}<0.06 ; \mathrm{r}=-0.12, \mathrm{p}<0.15)$. All items had a higher factor saturation than 0.30 . Table 3 compares several models. We compared the three-factor model of the shortened version of WASQ with an alternative model containing 1 factor and with a model containing two factors secure style with three items and insecure style with six items. We can say that only the model with three factors (secure, dismissive, and preoccupied) meets all the acceptance criteria. Internal consistency of secure style was alpha $=0.552$, dismissive style alpha $=0.761$ and preoccupied alpha $=0.739$.

Figure 1. Confirmatory factor analysis shortened version of WASQ.

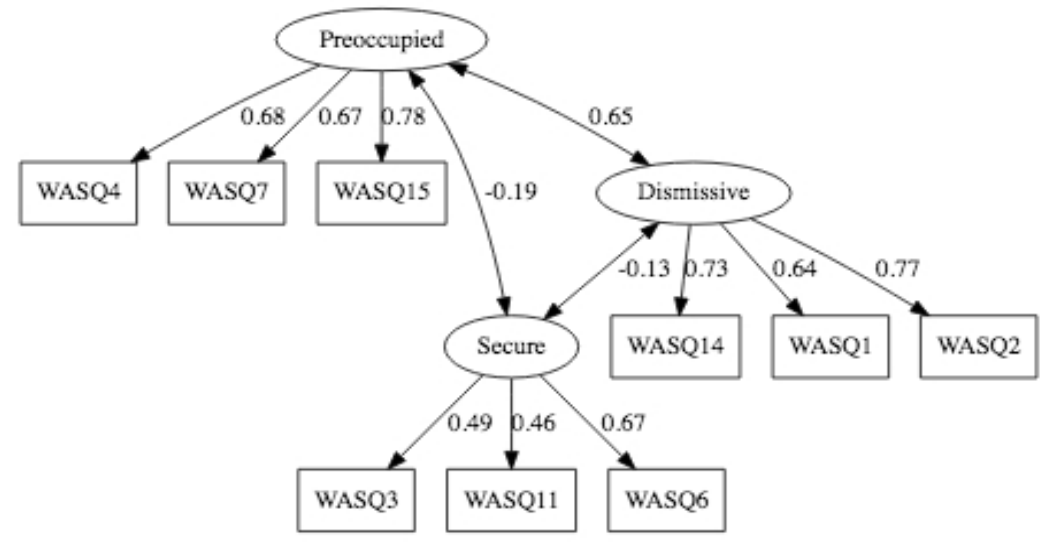

Table 3. Fit indices of confirmatory factor analysis.

\begin{tabular}{lllll}
\hline \hline Model & CFI & TLI & SRMR & RMSEA(lower-upper) \\
\hline \hline 1 factor & 0.680 & 0.573 & 0.113 & $0.170(0.151-0.189)$ \\
2 factors & 0.847 & 0.788 & 0.071 & $0.107(0.086-0.130)$ \\
3 factors & 0.966 & 0.950 & 0.053 & $0.052(0.020-0.080)$ \\
\hline \hline
\end{tabular}

\section{Discussion}

The paper aimed to examine the psychometric characteristics of the Slovak translation of the Workplace Attachment style questionnaire by Scrima (2018). The WASQ is the first questionnaire based on two-dimensionality, from which four types of attachment styles are derived. WASQ measures the intensity and quality of attachment to the workplace and bases it on Bowlby's classic attachment theory. The paper consists of two research studies. In study 1, we examined the construct validity of WASQ based on exploratory factor analysis. We extracted nine items from the original 15-item questionnaire, which formed the questionnaire's 3-factor structure with secure, dismissive, and preoccupied workplace attachment styles. The dimensions had high internal reliability, and the insecure styles correlated. There was also a positive relationship between organizational tenure and secure workplace attachment style. Within the gender, there was a small difference in the dismissive style. The confirmatory factor analysis in study 2 verified the suitability of the 3-factor structure of WASQ. The 9-item version of WASQ showed similar parameters as the original 15-item version (Scrima 2018). The study limit is the absent verification of discriminant and predictive validity with other instruments such as Experience in Close Relationships (Brennan et al. 1998) or Adult Attachment in the Workplace (Scrima, Rioux \& Lorito 2014). The WASQ can help HR managers to indicate whether employees feel safe in the workplace or not. In the event of insecure attachment styles, they could provide information on the need for interventions to increase the secure attachment and thus satisfaction and performance in the workplace (Scrima 2018). The situation changed dramatically around the world in the last year. The data in the presented paper were collected from February to April 2020, when the Covid pandemic was in its infancy. The subsequent nationwide lockdown in Slovakia began on March 12, 2020. With the onset of the Covid pandemic, several people moved their jobs to the home office. However, not everyone prefers to work from home, which could cause a reduction in the overall employees' performance and satisfaction. Therefore, it would be appropriate to examine how WASQ relates to performance and other organizational behavioral variables to predict the consequences of social isolation during the Covid pandemic. 


\section{References}

Ainsworth, M. S. (1979). Infant-mother attachment. American Psychologist, 34(10), 932-937, https://doi.org/10.1037/0003-066X.34.10.932

Bartholomew, K., \& Horowitz, L. M. (1991). Attachment styles among young adults: A test of a four-category model. Journal of Personality and Social Psychology, 61(2), 226-244. https://doi.org/10.1037/0022-3514.61.2.226

Bonaiuto, M., Fornara, F., \& Bonnes, M. (2003). Indexes of perceived residential environment quality and neighbourhood attachment in urban environments: a confirmation study on the city of Rome. Landscape and Urban Planning, 65(1-2), 41-52. https://doi.org/10.1016/s0169-2046(02)00236-0

Bowlby, J. (2010). Vazba - Teorie kvality ranných vztahů mezi matkou a dítétem. Praha: Portál.

Brennan, K. A., Clark, C. L., \& Shaver, P. R. (1998). Selfreport measurement of adult attachment: An integrative overview. In J. A. Simpson, W. S. Rholes (Eds.). Attachment theory and close relationships. (p. 46-76). New York: Guilford Press.

Brown, T. (2015). Confirmatory factor analysis for applied research. New York: Guilford Press.

Giuliani, M. V. (2003). Theory of attachment and place attachment. In M. Bonnes, T. Lee, \& M. Bonaiuto (Eds.), Psychological theories for environmental issues (pp. 137-170). New York: Routledge.

Hazan, C., \& Shaver, P. R. (1994). Attachment as an Organizational Framework for Research on Close Relationships. Psychological Inquiry, 5(1), 1-22. https://doi.org/10.1207/s15327965pli0501_1

Hu, L., \& Bentler, P. M. (1999). "Cutoff criteria for fit indexes in covariance structure analysis: Conventional criteria versus new alternatives". Structural Equation Modeling: A Multidisciplinary Journal. 6 (1), 1-55. https://doi.org/10.1080/10705519909540118

Levy, K. N. (2005). The implications of attachment theory and research for understanding borderline personality disorder. Development and Psychopathology, 17(4), 959-986. DOI: $10.1017 / \mathrm{s} 0954579405050455$

Main, M, Kaplan, N, \& Cassidy, J. (1985). Security in infancy, child- hood, and adulthood: A move to the level of representation. Monographs of the Society for Research in Child Development, 50(1-2), 66-104. https://doi.org/10.2307/3333827

Naništová, E. (1998). Človek a príroda: Enviromentálna psychológia. In.J. Výrost, I. Slaměník (Eds.). Aplikovaná sociální psychologie I. Portal.

Rioux, L. (2006). Construction of a scale of commitment to the workplace: An exploratory step. Canadian Journal of Behavioural Science - Revue Canadienne des Sciences du Comportement, 38, 325-336. doi:10.1037/cjbs2006018.

Rioux, L., \& Mokounkolo, R. (2005) Neighbourhood attachment and adolescence: a comparative study carried out in two neighbourhoods presenting a great cultural diversity. Bulletin de psychologie, 57(6), 611-620.

Scrima, F. (2018). The psychometric properties of the workplace attachment style questionnaire. Current Psychology. https://doi.org/10.4135/9781412963978.n256.

Scrima, F., Di Stefano, G., Guarnaccia, C., Lorito, L. (2015). The impact of adult attachment style on organizational commitment and adult attachment in the workplace. Personality and Individual Differences, 86, 432-437. https://doi.org/10.1016/j.paid.2015.07.013.

Scrima, F., Rioux, L., \& Di Stefano, G. (2017). I hate my workplace but I am very attached to it: workplace attachment style. Personnel Review, 46(5), 936-949. https://doi.org/10.1108/pr-052015-0128

Scrima, F., Rioux,L., \& Lorito, L. (2014). Three-factor structure of Adult Attachment in the Workplace: Comparison of British, French, and Italian samples. Psychological Reports: Sociocultural Issues in Psychology, 115,627-642.

Velasco, L., \& Rioux, L. (2010) Psychosocial approach to workplace attachment: a study carried out among hospital staff. Estudios de Psicologia, 31(3), 309-323. DOI: 10.1174/021093910793154385 